\title{
Financial precautions, carbon dioxide leakage, and the European Directive 2009/31/EC on carbon capture and storage (CCS)
}

\author{
Manuel Wifling ${ }^{1}[\mathbb{D}$ \\ Received: 22 June 2019 / Accepted: 19 October 2020 /Published online: 10 November 2020 \\ (C) The Author(s) 2020
}

\begin{abstract}
The phenomenon of anthropogenic climate change has been identified as a threat multiplier for many human-related concerns. Carbon capture and storage (CCS) can, in combination with several other mitigation technologies, alleviate global warming by reducing carbon dioxide $\left(\mathrm{CO}_{2}\right)$ emissions. Reducing climate change-related risks via CCS creates another risk, smaller in extent: the risk that some of the stored $\mathrm{CO}_{2}$ leaks out of the storage complex. This article reviews European legislation and evaluates how one of its objectives, that private liabilities of CCS-related leakage risks are not socialized, is ensured. Slight modifications of European legislation are suggested in order to prevent an indefinite liability of CCS operators in case a storage complex turns out to be unexpectedly and unavoidably prone to $\mathrm{CO}_{2}$ leakages. Official German and Hungarian financial precaution specifications are contrasted and related to this article's finding that the state budget is sufficiently hedged against the expected value of climate-related leakage compensation costs of poorly managed storage complexes if 3 to $6 \%$ of a CCS operator's emission-related revenues are diverted into a financial precaution fund.
\end{abstract}

Keywords Precautionary principle · Carbon dioxide leakage - CCS Directive · Directive 2009/31/ EC · Financial security $\cdot$ Transfer of responsibility

\section{Introduction}

At the Earth Summit in Rio de Janeiro in 1992, the parties to the United Nations Framework Convention on Climate Change have agreed to the objective of a "stabilization of greenhouse

Supplementary Information The online version contains supplementary material available at https://oi. org/10.1007/s10584-020-02904-1.

Manuel Wifling

Manuel.wifling@uni-hamburg.de; man_wifling@yahoo.de

1 Research Unit Sustainability \& Global Change, Universität Hamburg, Grindelberg 5,

20144 Hamburg, Germany 
gas concentrations in the atmosphere at a level that would prevent dangerous anthropogenic interference with the climate system." In the twenty-first Conference of the Parties in Paris, 2015, this objective was translated in Article 4 of the Paris Agreement into the goal of achieving "a balance between anthropogenic emissions by sources and removals by sinks of [greenhouse gases] in the second half of this century," thereby limiting maximum global warming to "well below $2^{\circ} \mathrm{C}$ " and pursuing "efforts to limit the temperature increase to $1.5^{\circ} \mathrm{C}$."

The "well below" $2{ }^{\circ} \mathrm{C}$ limit and, even more clearly, the $1.5^{\circ} \mathrm{C}$ target rely on the assumption that carbon dioxide removal (CDR) technologies will be broadly deployed (Horton et al. 2016; Fuss et al. 2018). CDR technologies can compensate both emissions sources for which no mitigation measures have been identified and excess historic emissions by achieving netnegative emissions after the mid-twenty-first century (IPCC 2018), thereby reducing the necessary pace of the reduction of anthropogenic greenhouse gas emissions and sustaining economic feasibility of the $2{ }^{\circ} \mathrm{C}$ limit and $1.5^{\circ} \mathrm{C}$ target. Two CDR technologies, afforestation/ reforestation and bio-energy carbon capture and storage (BECCS), are prominently deployed in Integrated Assessment Models (IAMs) (Smith et al. 2015; IPCC 2018). For BECCS, the carbon assimilated by photosynthesizing plants is released via combustion of biomass, captured endof-pipe, and isolated from the atmosphere by the carbon capture and storage (CCS) technology. Both CCS and BECCS are decisive technologies in the context of the $2{ }^{\circ} \mathrm{C}$ limit because if they were prohibited as mitigation technologies, mitigation costs would increase by $50-250 \%$ in idealized cost-effective IAM projections (IPCC (2014) fig. TS.13), and due to the ongoing delay of implementing sufficiently ambitious mitigation policies in the real world, ${ }^{2}$ the relevance of large-scale CDR technologies like BECCS may increase with time.

The technologies for $\mathrm{CO}_{2}$ capture, transport, and injection are readily available within the industrial sector as, for example, demonstrated by enhanced oil recovery (Faure and Partain 2017). However, real-world investment rates do not yet mirror a salient role of CCS/BECCS as mitigation technology (Koelbl et al. 2014). Besides social and political dynamics, CCS development is hampered by a lack of an effective market price for $\mathrm{CO}_{2}$ emissions in many parts of the world and remaining concerns and uncertainties on the scope of liabilities potentially entailed by leakages ${ }^{3} \&^{4}$ (Faure and Partain 2017). To enable CCS investments, it is crucial that exact terms of liability have been stated by the regulator and that leakage-related financial risks are modeled so that CCS operators ${ }^{5}$ can adequately forecast their business plans (Faure and Partain 2017).

This article relates the financial precaution requirements that are enshrined in the Directive 2009/31/EC of the European parliament and of the council of 23 April 2009 on the geological storage of carbon dioxide (referred to as the "CCS Directive") to leakage scenarios of Alcalde et al. (2018). Thereby, financial precaution specifications of the German and the Hungarian regulator are evaluated. The analysis focuses on climate-related costs only, i.e., the costs to

\footnotetext{
${ }^{1}$ As convention in this article, italic style quotes are from legally binding documents.

${ }^{2}$ The policy delay is well documented, e.g., by the UN Emissions Gap Report 2019 or the Climate Action Tracker (https://climateactiontracker.org/).

3 “'Leakage' means any release of $\mathrm{CO}_{2}$ from the storage complex (CCS Directive, Article 3(5))."

4 “' 'Storage complex' means the storage site and surrounding geological domain which can have an effect on overall storage integrity and security; that is, secondary containment formations (CCS Directive, Article 3(6))."

5 “' 'Operator' means any natural or legal, private or public person who operates or controls the storage site or to whom decisive economic power over the technical functioning of the storage site has been delegated according to national legislation (CCS Directive, Article 3(10))."
} 
surrender emissions allowances at the time of $\mathrm{CO}_{2}$ leakage. The Alcalde et al.'s (2018) leakage estimates are consistent with the early Intergovernmental Panel on Climate Change's (IPCC) suggestion in its 2005 special report on CCS that likely more than $99 \%$ of the stored $\mathrm{CO}_{2}$ is retained over 1000 years for "appropriately selected and managed" storage complexes (IPCC 2005). However, Alcalde et al. (2018) also modeled a worst-case scenario, where a regional or global CCS industry provides inappropriately selected and poorly managed storage solutions - an innovative scenario that is used in this article as basis for projecting worstcase climate-related financial risks.

Gerard and Wilson (2009) and the Hungarian regulator (European Commission 2014) utilize existing financial precaution instruments of oil and gas and mining activities, comprising financial precaution amounts below 1 million US dollars $(\$ 1 \mathrm{M})$, as a complement or guideline of CCS regulation. ${ }^{6}$ This approach is critically evaluated and contrasted with official German legislation. The German legislation on CCS, i.e., the "Gesetz zur Demonstration und Anwendung von Technologien zur Abscheidung, zum Transport und zur dauerhaften Speicherung von Kohlendioxid" (hereafter referred to as "CCS-Act"), obliges CCS operators to put $3 \%$ of the emissions-related revenues into an interest-bearing deposit account.

In addition, this article highlights a potential shortcoming of the CCS Directive's Article 18 on the "Transfer of Responsibility" from a CCS operator to the competent authority (CA).

In general, the deployed model is designed so as to reflect a regulatory environment that is consistent with the Paris Agreement and the CCS Directive. In contrast to the widespread research method to model key parameters endogenously in an IAM (e.g., Vinca et al. 2018), this article transparently integrates all parameters exogenously.

The article is organized as follows. Section 2 defines key concepts necessary to reflect a span of plausible real-world regulator's financial precaution assumptions. Section 3 introduces relevant aspects of the European CCS regulatory framework and the German and Hungarian legislative interpretation of the CCS Directive's financial precaution requirements. Section 4 defines a financial precaution fund scheme consistent with the CCS Directive and justifies the assumed model parameters by highlighting key arguments that constitute them. Section 5 shows financial modeling results which are discussed in Section 6 regarding to real-world policy implications.

\section{Definitions}

Two conceptual models - event-based leakage and exponential leakage - are especially useful for scenario analysis. These and four real-world leakage circumstances, taking into account whether leakages can be remedied or avoided, are defined as follows:

Event-based leakage Leakage events, e.g., an injection well failure, are modeled to occur each year with a certain probability. They lead to log-normally distributed amounts of $\mathrm{CO}_{2}$ escaping the storage complex. The log-normal distribution is characterized by a heavy tail, i.e., by non-negligible probabilities assigned to high-volume leakage events.

\footnotetext{
${ }^{6}$ Discussions of financial precaution instruments are frequently lead in economic literature under the term "bonding" (e.g., Held et al. 2006; Hanley et al. 2007).

7 Translation: Law on the demonstration and application of technologies for capture, transport and permanent storage of carbon dioxide.
} 


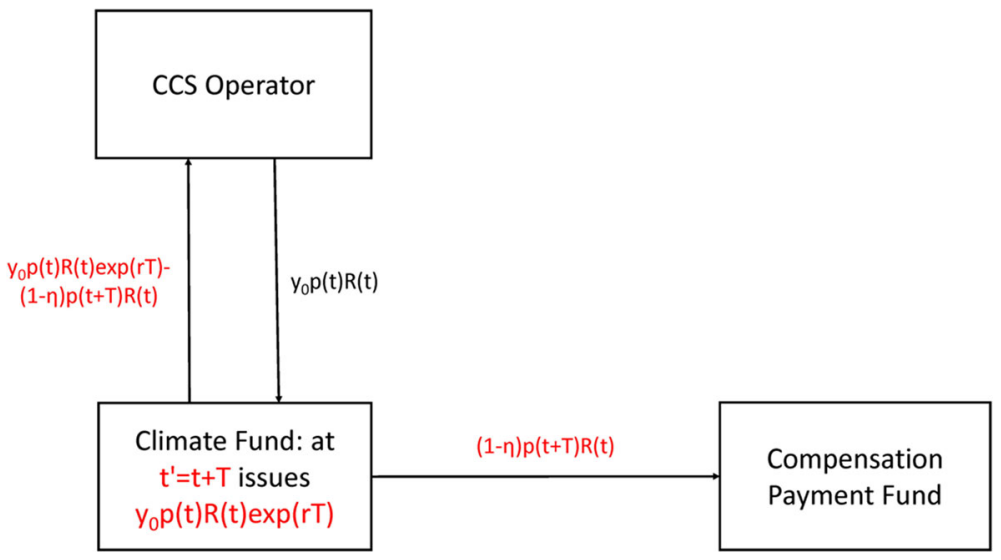

Fig. 1 Graphical illustration of a financial precaution regulation of climate-related leakage risks, designed compatible with the CCS Directive. Installment payments into the climate fund are deducted from the emissions-related revenues $\mathrm{p}(\mathrm{t}) \mathrm{R}(\mathrm{t})$ of the CCS operator. At the time $t$ ' of uncertainty reduction (in red), the climate fund is used to feed the compensation payment fund that finances compensation of the now known leakage-related climate costs. The excess amount of the climate fund is payed back to the CCS operator

Exponential leakage The leakage profile entailed by a $\mathrm{CO}_{2}$ injection pulse is described by an exponential decay function: $L(t)=l R_{0} \exp (-l t)$, with the leakage flux $L(t)$, the (constant) leakage rate $l$, the sequestration pulse mass $R_{0}$, and the time $t$ after the $\mathrm{CO}_{2}$ injection pulse.

Remediable leakage After the occurrence and detection of $\mathrm{CO}_{2}$ leakage, remediation activities can always eliminate the source of $\mathrm{CO}_{2}$ leakage.

Irremediable leakage After the detection of $\mathrm{CO}_{2}$ leakage, no remediation mechanism can eliminate the source of $\mathrm{CO}_{2}$ leakage.

Unavoidable leakage Even if firms are well-regulated and operating according to all regulatory requirements, some unavoidable leakage occurs.

Avoidable leakage All leakage that could be prevented, either by a better regulatory framework or by full compliance of firms with existing regulatory requirements, is called avoidable leakage.

In Guidance Document 4 on the implementation of the CCS Directive, the method of determining financial security (FS) amounts is based on the concept of event-based leakage (Fig. 1 in European Commission and Climate Action DG) 2011d). This article approximates a complex process-based leakage model of Alcalde et al. (2018), describing both avoidable and unavoidable leakages by the concept of exponential leakage.

\section{European CCS legislation}

The European CCS Directive is based on a so-called stage-gate approach (European Commission and Climate Action DG 2011a). Each storage project of a CCS operator is subdivided into stages or phases (Fig. 1 in European Commission and Climate Action DG 
2011a). The phases include the assessment of the storage capacity of the reservoir (phase 1), the characterization of the storage site and the wider storage complex (phase 2), the development of storage infrastructure and facilities required for $\mathrm{CO}_{2}$ injection (phase 3), the operation of the injection wells (phase 4), the closure of the injection well and subsequent monitoring whether compliance of the storage site's performance profile with ex ante agreed conditions is fulfilled (phase 5), and the management of the storage site by the CA after the transfer of responsibility from the CCS operator to the CA has occurred (phase 6). The duration of phases one to five depends on site-specific assessment and risk management plans but may typically span 50-70 years (European Commission and Climate Action DG 2011a). Phase 6-state ownership of responsibility and risks - continues until the $\mathrm{CO}_{2}$ is rendered immobile by natural immobilization mechanisms, which occurs on the 10,000-year time-scale (Alcalde et al. 2018).

The remainder of this section introduces the financial precaution measures that are prescribed by the CCS Directive and highlighted in Guidance Document 4. CCS operators are subjected to FS obligations, which hedge the state against potentially inflicted costs until phase 5, and to financial contribution (FC) obligations, which take into account costs borne by the CA in phase 6 (European Commission and Climate Action DG 2011d).

\subsection{The Article 19 Financial Security}

The intent behind the Article 19 Financial Security (FS) of the CCS Directive is to ensure that the costs related to monitoring, safety, environmental and other obligations are covered and thus do not impose financial risks on the taxpayer if CCS operators are unable to fulfill these obligations (European Commission and Climate Action DG 2011d). A combination of deposits, irrevocable trust funds, escrow accounts, payment or performance bonds, bank guarantees or letters of credit, EU emissions allowances, and insurance solutions were discussed as FS instruments (European Commission and Climate Action DG 2011d). Consistent with the scientific literature (Wilson et al. 2009; Faure and Partain 2017), Guidance Document 4 recommended insurance solutions where possible but underlined uncertainty whether requirements for commercial insurance to cover leakage-related climate risks may once be fulfilled (European Commission and Climate Action DG 2011d).

The FS instruments can be "periodically adjusted to take account of changes to the assessed risk of leakage and the estimated costs of all obligations (CCS Directive, Article 19(2))," including the obligation to surrender EU emissions allowances in case leakages occur. The larger the total $\mathrm{CO}_{2}$ mass in the storage complex, the larger are potential leakages. Thus, phased FS instruments, where fund amounts are built up as the total injection volume increases with time, can be a part of the FS instrument set (European Commission and Climate Action DG 2011d).

When determining FS amounts, the technique of "expected value," calculating the sum over all potential costs multiplied by their respective probabilities, should be used with care (European Commission and Climate Action DG 2011d). "Such [expected value] techniques apply probability weightings to costs of obligations that are uncertain to arise, such as costs of corrective measures, surrender of allowances, temporary operation of the site, and the like. A problem with applying such techniques to very low probability events is that the resulting expected values may be much too small to provide sufficient coverage via FS in the event that the obligation does arise (European Commission and Climate Action DG 2011d)." Guidance Document 4 specified a $20 \%$ likelihood that FS amounts are too low for financing the surrender of EU emissions 
allowances as "significant," without rigorously defining what is meant by this term, leaving open for the Member State's CA to decide which threshold may represent an acceptable financial risk (European Commission and Climate Action DG 2011d).

\subsection{The Article 20 Financial Mechanism}

The financial contribution (FC) "from the operator shall take into account [...] elements relating to the history of storing $\mathrm{CO}_{2}$ relevant to determining the post-transfer obligations, and cover at least the anticipated cost of monitoring for a period of 30 years (CCS Directive, Article 20(1))." Only if the FC has been built up by the operator, the FS is paid back (CCS Directive, Article 19(3)(b)(ii)), and the transfer of responsibility takes place (CCS Directive, Article 18(1)(c)). The FS should in substance also cover the FC for, otherwise, in case an operator is insolvent or bankrupt and the FS already used up to meet the obligations of the CCS Directive, the taxpayer would bear the financial burden related to the FC (European Commission and Climate Action DG 2011d).

Notwithstanding the FC must finance at least the anticipated cost of monitoring for a period of 30 years, FC amounts may be determined on basis of the full costs borne by the CA in the posttransfer period (phase 6), accounting for (i) longer monitoring periods than 30 years, (ii) corrective measures, (iii) the surrender of allowances in the event of leakages, and (iv) costs under Directive 2004/35/EC, a Directive on environmental liability with regard to the prevention and remedying of environmental damage (European Commission and Climate Action DG 2011d). The operational costs of monitoring depend on the site-specific monitoring plans submitted and updated under the CCS Directive (European Commission and Climate Action DG 2011b) but may be on the order of a few million dollars per year (based on Bolhassani et al. 2017).

\subsection{The Article 18 Transfer of Responsibility}

For a storage complex, monitoring and, if necessary, remediation activities could need to be performed over millennial time scales (Wilson et al. 2008), while the life-times of private firms are shorter (Adelman and Duncan 2011). Hence, organizing a way of transferring responsibility and liability to an agent with a long life time - the nation state and its $\mathrm{CA}$ - is vital for ensuring safe long-term storage of $\mathrm{CO}_{2}$ (Faure and Partain 2017) and that national leakage liabilities remain assigned in sight of European or international climate commitments. The main condition enabling a transfer of responsibility is that "all available evidence indicates that the stored $\mathrm{CO}_{2}$ will be completely and permanently contained (CCS Directive, Article 18(1)), " which shall be demonstrated by the operator by reporting "the conformity of the actual behavior of the injected $\mathrm{CO}_{2}$ with the modeled behavior, the absence of any detectable leakage", and by reporting "that the storage site is evolving towards a situation of long-term stability (CCS Directive, Article 18(2)(a)\&(b)\&(c))." Notwithstanding that a minimum time period of 20 years of the post-closure phase is given in the CCS Directive (CCS Directive, Article 18(2)), the elapsed time is not seen as a decisive criterion for enabling the transfer of responsibility but conformance with the ex ante agreed performance-based criteria of Article 18(2)(a), (b), and (c) (European Commission and Climate Action DG 2011c).

\subsection{German and Hungarian financial precaution specifications}

Most EU Member States directly adopted Articles 19 and 20 into national legislation (European Commission 2014). However, Hungary has set an amount of 200 million 
Hungarian Forint (HUF) as minimum FS, based on existing national regulation for mining (around $647,000 €$ or $731,000 \$^{8}$ ) (European Commission 2014). Furthermore, Germany specified in its CCS-Act in $\S 30$ and $\S 31$ that the operator must pay $3 \%$ of the emissions-related revenues, i.e., the revenues that stem from the saved emissions certificates, at the end of each year into an interest-bearing deposit account (Bundestag 2012). The operator can draw from the deposit account for FS purposes in a subordinated manner. However, the withdrawn financial amounts have to be reestablished without delay, and once the transfer of responsibility takes place, the full amount of the deposit account, including the earned interests, is transferred to the CA as FC, which represents a lump-sum fee that is not performance-based.

\section{Materials and methods}

The regulator's objective of hedging the state against a socialization of financial risks can be ensured for climate-related risks if, for a known anticipated leakage flux $L(t)$, the CCS operator is obliged to pay the following fraction $(1-\eta)$ of emissions-related revenues $p(t) R(t)$ into a financial precaution fund:

$$
1-\eta=1-\frac{N P V_{L>0}}{N P V_{L=0}}=\frac{\int_{0}^{\infty} p(t) L(t) \exp (-r t) d t}{\int_{0}^{\infty} p(t) R(t) \exp (-r t) d t}
$$

with the net present value $N P V_{L>0}$ under a positive leakage flux $L(t)$, the net present value $N P V_{L=0}$ in case of no leakages, the carbon permit price trajectory $p(t)$, the $\mathrm{CO}_{2}$ sequestration rate $R(t)$, the discount rate $r$, and the effectiveness of temporary $\mathrm{CO}_{2}$ storage $\eta$ (Herzog et al. (2003), Ha-Duong and Keith (2003), and Teng and Tondeur (2007) also used the NPV concept as basis of an economic analyses of the leakage problem). In the NPV concept, the discounted sequestration-related benefits $p(t) R(t) \exp (-r t)$ subtracted with the discounted leakage emissions-related costs $p(t) L(t) \exp (-r t)$ are integrated over time.

Figure 1 shows a financial precaution fund scheme compatible with the CCS Directive's Article $19 \mathrm{FS}$ and Article $20 \mathrm{FC}$ by taking into account a prolonged period $T$ of uncertainty about a storage complex's leakage behavior. The uncertainty assigned to the $\mathrm{CO}_{2}$ mass of an injection pulse prevails for $T$ years after that pulse and is assumed to be fully reduced thereafter. A fraction $y_{0}$ of the emissions-related revenues $p(t) R(t)$ is diverted into a climate fund. This fund is not under the control of the operator. It invests the financial amounts according to an ex ante agreed investment strategy, leading to financial growth at a rate $r$. The fraction $y_{0} \in[0,1]$ is a choice variable of the regulator reflecting the strictness of financial precaution assumptions. If $y_{0}=0$, the regulator believes that firms deliver complete and permanent containment of the stored $\mathrm{CO}_{2}$, while for $y_{0}=1$, all injected $\mathrm{CO}_{2}$ is regarded as potentially prone to leakages. At the time $t^{\prime}=t+T$ (Fig. 1 in red), learning about the storage complex's leakage profile has occurred, and the blocked financial amount $y_{0} p(t) R(t) \exp (r T)$ is released. One part of this released amount is used to compensate all past and future leakagerelated climate costs by paying $(1-\eta) p(t+T) R(t)$ into a compensation payment fund. The remaining financial share of the climate fund is paid back to the CCS firm. In order to model

\footnotetext{
${ }^{8}$ Based on 2017 exchange rates given by the European Central Bank https://www.ecb.europa.eu/stats/policy_ and_exchange_rates/euro_reference_exchange_rates/html/eurofxref-graph-huf.en.html and Statista https://www. statista.com/statistics/412794/ euro-to-u-s-dollar-annual-average-exchange-rate/. Accessed 10 November 2018
} 
the above financial fund amounts explicitly, further parameter assumptions are clarified and justified in the remainder of this section.

The carbon price trajectory $p(t)$ relies on the median IAM projections compiled by the IPCC (2014). To a good approximation, the IPCC's carbon price grows at a constant rate of $4.5 \%$ year until $2100 \mathrm{AD}$ from $80 \$ / \mathrm{tCO}_{2}$ in $2030 \mathrm{AD}$ to $1867 \$ / \mathrm{tCO}_{2}$ in $2100 \mathrm{AD}$. Beyond $2100 \mathrm{AD}$, this article sets the carbon price as a constant of $1867 \$ / \mathrm{tCO}_{2}$ because it is assumed that backstop technologies have deeply penetrated into the markets at such a price. Backstop technologies can reduce demand for $\mathrm{CO}_{2}$ emissions permits by substituting fossil emissions-based technologies by emissions free technologies. Carbon dioxide removal (CDR) technologies are also considered as backstop technologies (Herzog et al. 2003). They increase supply of admissible $\mathrm{CO}_{2}$ emissions amounts for a given, finite emissions budget consistent with the $2{ }^{\circ} \mathrm{C}$ limit. Given that a combination of multiple CDR technologies could deliver up to maybe $15 \mathrm{GtCO}_{2} /$ year for a price below $300 \$$ / $\mathrm{tCO}_{2}$ by $2050 \mathrm{AD}$ (based on Fuss et al. 2018; IPCC 2018), a match of demand and supply for admissible $\mathrm{CO}_{2}$ emissions could plausibly occur at a price lower than the assumed $2100 \mathrm{AD}$ carbon price stabilization level of $1867 \$ / \mathrm{tCO}_{2}$. In any case, once the Paris Agreement's objective of net zero anthropogenic emissions in the second half of this century is reached, the carbon price will be fully determined by demand and supply of negative emissions and thus by marginal cost curves of backstop technologies. If society refrains from using CDR technologies, a net zero emissions aim would necessitate gross zero emissions, which could only be supported by an infinitely high carbon price because all emissions sources, no matter how hard to mitigate, would need to be eliminated. Thus, the concepts of $N P V$ and $\eta$ are only applicable when describing a future economy subjected to the Paris Agreement in which CDR technologies are deployed. Otherwise, the leakage-related climate costs would be infinite in the second half of this century, and the NPV integral diverges. In sight of the relevance of CDR technologies for optimal short-term and optimal and real-world longterm carbon prices, this article also models a scenario in which the carbon price only stabilizes by $2125 \mathrm{AD}$ at $5750 \$ / \mathrm{tCO}_{2}-\mathrm{a}$ carbon price that on the one hand side roughly equates maximum 2100 AD carbon price estimates (IPCC 2014) but, on the other hand, may represent a world in which CDR technologies turn out to be less feasible than currently assumed in most IAMs.

The discount rate $r$ should be determined on the basis of the rate of return on investment of the financial precaution fund, ensuring that anticipated costs can be covered by the fund. Piketty (2014) introduced a so-called pure rate of return on investment, given by the average rate of return on investment minus all informal costs related with asset management. The historical pure rate of return on investment has been remarkably stable between 4 and 5\% across different countries and economic circumstances (Piketty 2014). This article deploys a discount rate of $4.5 \%$ year, representing an average investment strategy.

On an economy-wide macro-scale, the $\mathrm{CO}_{2}$ sequestration rate $R(t)$ is assumed consistent with an ensemble of IAMs for $2{ }^{\circ} \mathrm{C}$ limited, cost-effective projections (Koelbl et al. 2014). Significant sequestration occurs after $2030 \mathrm{AD}$, following to a good approximation a square root functional form of $3.6 \mathrm{GtCO}_{2} / \mathrm{yr}^{3 / 2} \sqrt{t-2030}$ until $2100 \mathrm{AD}$. This choice is also consistent with the European regulator's expectation that CCS in the fossil fuel power sector will be necessary for reaching decarbonization targets from around 2030 AD onwards (European Commission 2015). The cumulative sequestration amount in this article's model setup is $1420 \mathrm{GtCO}_{2}$ by the end of this century.

On a single storage complex-based micro-scale, the $\mathrm{CO}_{2}$ sequestration rate $R(t)$ is set as $1 \mathrm{MtCO}_{2}$ /year between 2030 and $2060 \mathrm{AD}$. The 30-year time horizon is similarly assumed by Alcalde et al. (2018) and consistent with the typical life-cycle time horizons of CCS projects, as given in the Guidance Document 1 of the CCS Directive. The rate $1 \mathrm{MtCO}_{2} /$ year coincides with 
the (European Commission and Climate Action DG 2011a) capture rate of the first large-scale BECCS facility, which commenced operation as a demonstration plant in the USA, Illinois, in April 2017 (Global CCS Institute 2018). It furthermore is roughly consistent with the sequestration rates exhibited by the Norwegian storage reservoirs Sleipner (in the North Sea) and Snøhvit (in the Barents Sea) as well as by the Algerian storage reservoir In Salah (in the Sahara), where sequestration wells injected several $100 \mathrm{ktCO}_{2} /$ year, respectively (Eiken et al. 2011). ${ }^{9}$

For the macro-scale projections, precautionary fund amounts are given in units of percent of gross domestic product (GDP). The United Nations central scenario projections indicate a global GDP growth of 3.5\%/year until $2030 \mathrm{AD}$, a then following 3.1\%/year until $2050 \mathrm{AD}, 1.7 \%$ year until $2070 \mathrm{AD}$, and 1.4\%/year until $2100 \mathrm{AD}$ (Piketty 2014). For projections beyond $2100 \mathrm{AD}$, this article assumes a constant rate of $1.4 \%$ year, because the two main factors causing the decrease of world GDP growth rates in the twenty-first century - catch-up growth of developing and emerging economies and a world-wide demographic transition - are believed to be largely completed by the end of this century in the UN central scenario (Piketty 2014).

The leakage model in this article is derived from results of a numerical Monte Carlo program of Alcalde et al. (2018), called storage security calculator. The storage security calculator estimates, inter alia, time-dependent leakage fluxes across a regional or global, onshore CCS industry. It includes immobilization processes from residual trapping, solubility trapping of $\mathrm{CO}_{2}$ into brine, and mineralization (Alcalde et al. 2018). In one scenario, the CCS industry was assumed to be "poorly regulated," where man-made leakage pathways, particularly abandoned and improperly sealed legacy wells, prevail. In the second, "well-regulated" scenario, monitoring and remediation activities were effectively preventing the occurrence of avoidable leakages. Alcalde et al. (2018) published leakage estimates as the leaked fraction (LF) values after the time of a storage site's $\mathrm{CO}_{2}$ injection commencement. The Alcalde et al.'s (2018) "well-regulated" and "poorly regulated" scenarios are utilized in this article but called "wellmanaged" and "poorly managed" in order to underline the principle responsibility and liability of the CCS operator for ensuring safe $\mathrm{CO}_{2}$ storage under the CCS Directive. In this article, the Alcalde et al.'s (2018) leakage model is simplified by deploying an impulse response model and exponential leakage with a constant leakage rate $l$. The leakage rates are step-wise adjusted at year 100 and 1000 after the $\mathrm{CO}_{2}$ injection pulse and fitted so as to match the published Alcalde et al. (2018) leaked fraction values at year 100,1000, and 10,000, respectively. The resulting P50 (P05) estimates indicate that 50\% (5\%) of the modeled leakage values are larger than the displayed value (leakage values are displayed in Online Appendix, Table 1). In order to transparently illuminate the maximal error of this model simplification, given that the Alcalde et al.'s (2018) leakage rates are decreasing with time, also a (unrealistic) worst-case leakage behavior is modeled where the cumulative 100-year P50 value of "poorly managed" storage reservoirs is assumed to occur over the first 33 years (with $l_{w c}=0.202 \%$ ). Thereafter, between year 34 and year 100 after a given injection pulse, the leakage flux is assumed as zero.

\section{Results}

For a given $\mathrm{CO}_{2}$ injection pulse, the above defined modeling setup (visualized in Fig. 1) entails an analytical solution for the effectiveness $\eta$ of temporary $\mathrm{CO}_{2}$ storage and for the compensation payment fund (Online Appendix).

\footnotetext{
${ }^{9}$ Ringrose et al. (2013) present a summary of the legacy and the "lessons learned" from the In Salah CCS project.
} 


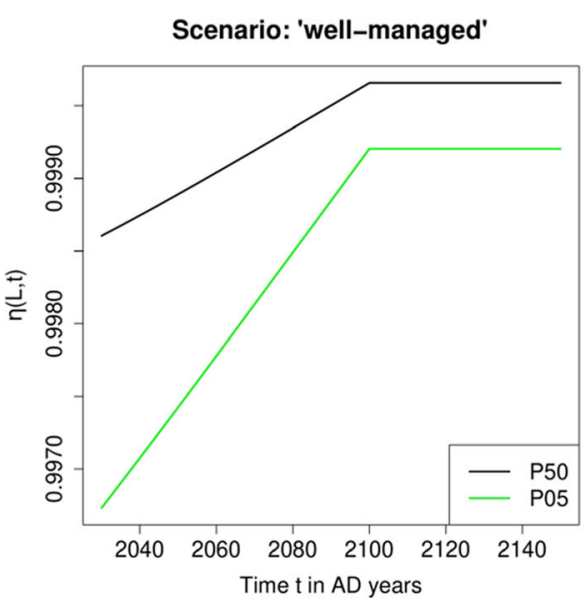

(a)

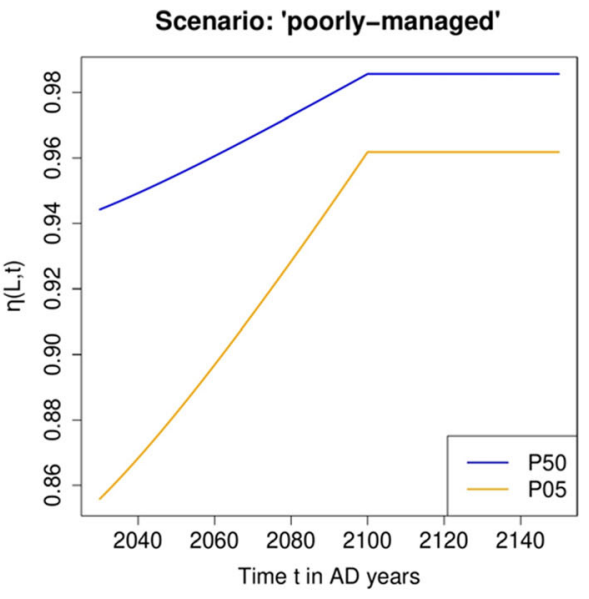

(b)

Fig. 2 Effectiveness $\eta=\eta(L, t)$ of temporary $\mathrm{CO}_{2}$ storage, as defined on basis of the net present value concept, for a $\mathrm{CO}_{2}$ injection pulse at time $t$ and a leakage flux $L(t)$ associated to a "well-managed" (a) and "poorly managed" (b) storage site, respectively. Note the different scales of the $y$-axes

The effectiveness $\eta$ is a function that depends on the assumed leakage scenario and the time of $\mathrm{CO}_{2}$ injection (Fig. 2). The "well-managed" scenarios exhibit an effectiveness larger than 99.6\%. The "poorly managed" scenarios induce significantly lower values between 85.6 and $98.6 \%$ (Fig. 2).

When superimposing yearly injection pulses, the evolution of the compensation payment fund reflects the stock of the financial climate risks that results from the two assumed leakage scenarios of "well-managed" and "poorly managed" storage complexes. Figures 3 and 4 project amounts of the compensation payment fund fed by either a share $(1-\eta)$ or a lumpsum $3 \%$ or $6 \%$ share of emissions-related revenues $p(t) R(t)$, while assuming instantaneous uncertainty reduction $(T=0)$.

\subsection{Macro results}

Based on the given global assumptions, the compensation payment fund increases over time to around $0.2 \% \mathrm{GDP}_{2100 \mathrm{AD}}\left(10 \% \mathrm{GDP}_{2100 \mathrm{AD}}\right)$ in the "well-managed" ("poorly managed") leakage scenario (Fig. 3a and b). ${ }^{10}$ By construction of the modeling setup, fund amounts are decreasing towards zero thereafter. The installment payments reach a maximum of around $0.004 \% \mathrm{GDP}_{2100 \mathrm{AD}}\left(0.2 \% \mathrm{GDP}_{2100 \mathrm{AD}}\right)$ in the "well-managed" ("poorly managed") scenario (Online Appendix, Fig. 5). In real, 2010 AD-based dollars, the compensation payment fund grows to around 1 trillion \$ (50 trillion \$) for the "well-managed" ("poorly managed") scenario by $2100 \mathrm{AD}$ or, equivalently, to around $1 \$(30 \$)$ per cumulatively stored ton of $\mathrm{CO}_{2}($ Online Appendix, Figs. 6 and 7).

If a compensation payment fund is fed by lump-sum $3 \%$ emissions-related installment payments, it amasses around $15 \% \mathrm{GDP}_{2100 \mathrm{AD}}$ in the "well-managed" leakage scenario (Fig. 3c)

\footnotetext{
${ }^{10}$ For describing the graphs, I typically depict the maximum fund value on the temporal axis and values somewhat between the P50 and P05 value on the $y$-axis because they are indicative for the expected value of the underlying heavy tail-shaped leakage distribution of Alcalde et al. (2018).
} 


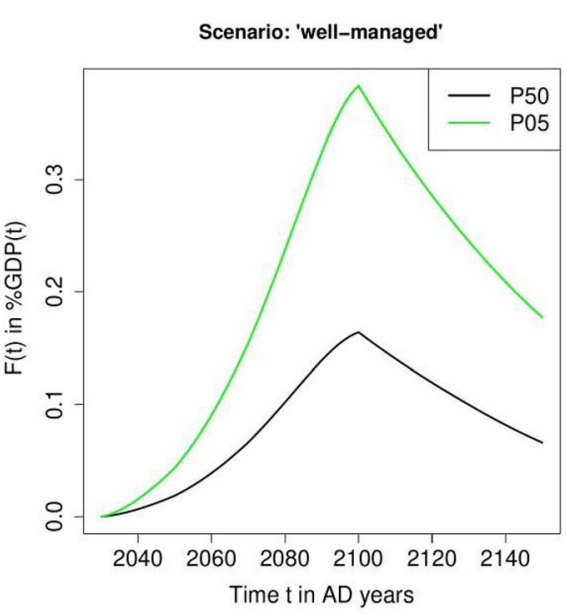

(a)

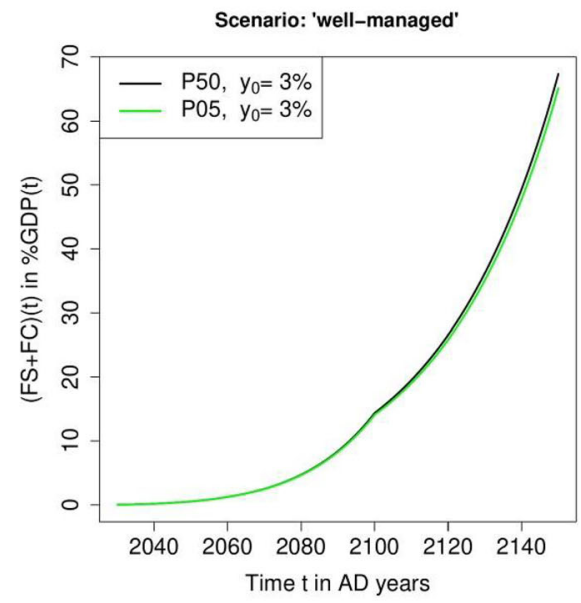

(c)

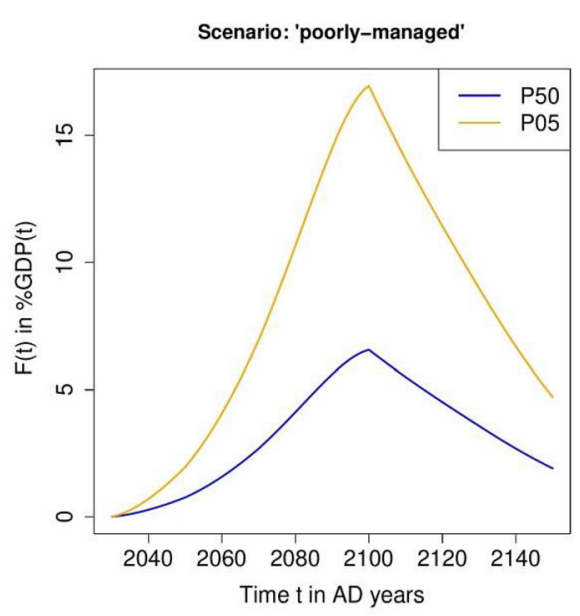

(b)

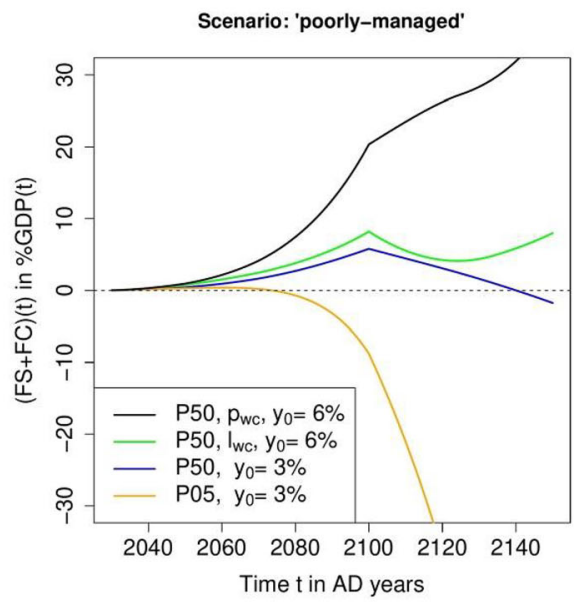

(d)

Fig. 3 Macro-scale evolution of the compensation payment fund - a fund dedicated to finance compensation of climate-related leakage costs. For figures (a) and (b), emissions-related installment payments of $(1-\eta(t)) p(t) R(t)$ are diverted into the fund, which consequently can compensate all climate-related leakage costs. Figures $(\mathbf{c})$ and (d) show how a fund fed by installment payments of $y_{0} p(t) R(t)$ evolves if devoted to compensate all climaterelated leakage costs and hence if devoted to combined FS and FC purposes. The worst-case leakage scenario $l_{w c}$ illuminates the maximal error that may result from the chosen model simplification. $p_{w c}$ denotes a pessimistic carbon price evolution. Note the different scales of the $y$-axes

by the end of the twenty-first century and diverges thereafter. The $15 \% \mathrm{GDP}_{2100 \mathrm{AD}}$ is still a small amount relative to the combined global public and private capital stock, which is and will be around 3-7 times GDP (based on Piketty 2014). The lump-sum 3\% installment payments could finance a significant share of climate-related leakage costs of "poorly managed" storage complexes (Fig. 3d). The P50 value becomes negative only in 2140 AD and hence 40 years after the last injection facility is assumed as closed. In contrast, installment 
payments of $6 \%$ could even compensate an assumed (unrealistic) worst-case leakage behavior or, alternatively, climate-related leakage costs in a world at which carbon prices stabilize only by 2125 at $5750 \$ / \mathrm{tCO}_{2}$.

For the official German regulation, where the $3 \%$ of the emissions-related revenues are cumulated in time and used for financing obligations that arise after the transfer of responsibility while earlier leakages have to be financed by separate FS instruments, FC amounts are found to be much larger than the potentially inflicted climate-related financial risks. When assuming the transfer of responsibility to occur 50 years after a given injection pulse, the German FC amounts are diverging towards infinity even for the P05 value of "poorly managed" storage complexes (Online Appendix, Fig. 9).

The climate fund (visualized in Fig. 1) is modeled on the basis of a gradual uncertainty reduction of a storage complex's leakage profile, where the uncertainty associated to the stored $\mathrm{CO}_{2}$ of an injection pulse is assumed as reduced 20 years after that pulse. The fraction $y_{0}$ of installment payments is chosen on the basis of potentially inflicted climate costs, i.e., $y_{0}=(1-\eta)$, with $\eta$ being based on either the P05 leakage value of "well-managed" complexes or on the P50 or P05 leakage value of "poorly managed" complexes. Furthermore, it is assumed that effective regulation, of which precautionary fund approaches can be a part of, forces all CCS operators to provide "well-managed" storage solutions. Thus, the P50 leakage compensation costs are continuously deducted from the fund. One finds that the climate fund roughly amasses half of the amounts displayed in Fig. $3 \mathrm{a}$ and b by 2100 AD (Online Appendix, Fig. 10). From 2100 to 2120 AD, by assumption, the fund shrinks towards the P50 curve of Fig. 3a and follows the P50 value thereafter.

\subsection{Micro results}

In the micro modeling setup, a 30-year sequestration period from 2030 to $2060 \mathrm{AD}$ and a 20year post-closure period until $2080 \mathrm{AD}$ is assumed. In $2080 \mathrm{AD}$, after the transfer of responsibility, the fund amounts can be handed over to the CA. Figure $4 \mathrm{a}$ and $\mathrm{b}$ display the discounted fund amounts which indicate how much a CCS operator would need to pay into a compensation payment fund at time $2030 \mathrm{AD}$ if all climate-related leakage costs beyond the time $t$ were to be compensated by that fund. At time 2060 AD, the 2010 AD-based, real discounted compensation payment fund amounts are maximal and reach around \$3 M ( $\$ 125 \mathrm{M})$ for the case of a "well-managed" ("poorly managed") storage complex. These amounts translate into \$12 M (\$500 M) in $2060 \mathrm{AD}$ and \$20 M (\$750 M) in $2080 \mathrm{AD}$ (Online Appendix, Fig. 3).

Lump-sum 3\% emissions-related installment payments lead to maximum discounted compensation payment fund amounts of $\$ 73 \mathrm{M}$ by $2060 \mathrm{AD}$ in the "well-managed" leakage scenario (Fig. 4c), corresponding to real dollar amounts of around \$300 M in 2060 AD and leading to amounts of \$700 M in 2080 AD (Online Appendix, Fig. 3). The yearly emissionsrelated installment payments $3 \% p(t) R(t)$ increase from $\$ 2 \mathrm{M}$ in $2030 \mathrm{AD}$ to $\$ 9 \mathrm{M}$ in $2060 \mathrm{AD}$ (Online Appendix, Fig. 2). Figure 4d shows that, for the P50 leakage value of "poorly managed" storage complexes, the $3 \%$ emissions-related installment payments suffice as FS amounts for financing climate compensation over a 50-year time horizon, until 2080 AD when the time of transfer of responsibility may occur, but are too low to feed a FC that compensates leakage-related climate costs beyond 2091 AD. 


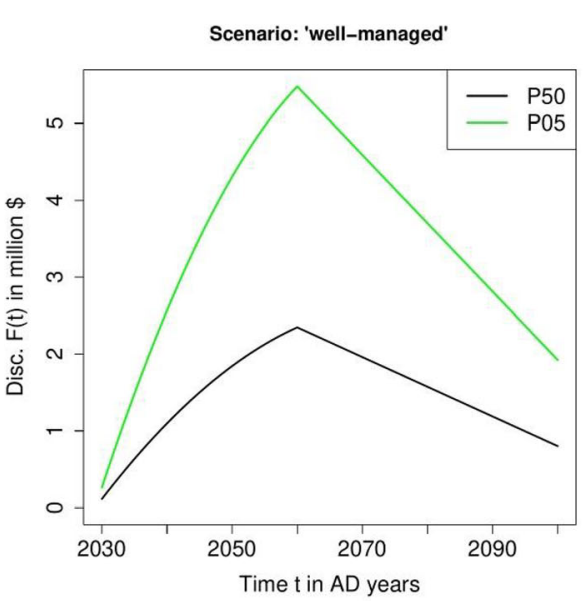

(a)

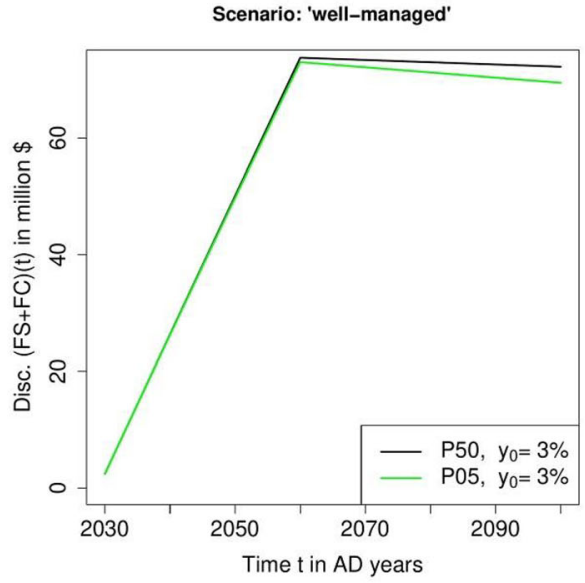

(c)

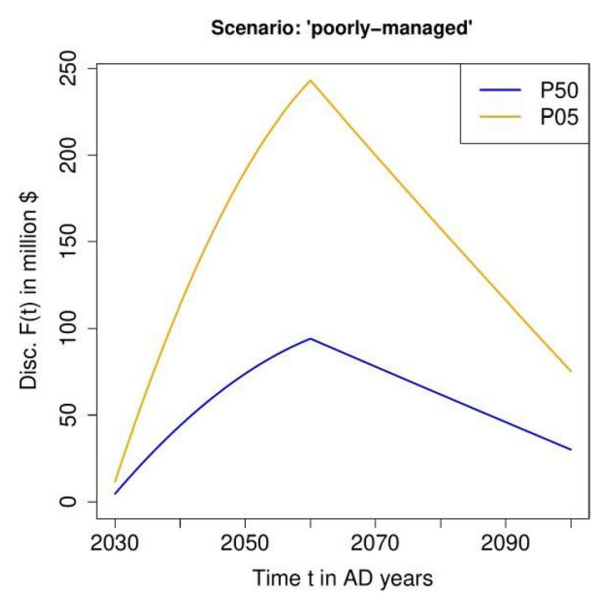

(b)

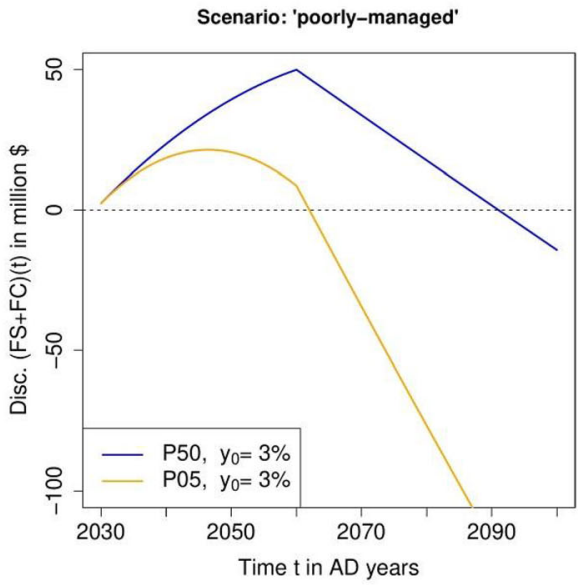

(d)

Fig. 4 Micro-scale evolution of the discounted compensation payment fund, with Disc. $F(t)=\exp (4.5 \%(t-$ 2030)) $F(t)$. For figures (a) and (b), emissions-related installment payments of $(1-\eta(t)) p(t) R(t)$ are diverted into the fund, which consequently can compensate all climate-related leakage costs. Figures (c) and (d) show how a fund fed by installment payments of $3 \% p(t) R(t)$ evolves if devoted to compensate all climate-related leakage costs and hence if devoted to combined FS and FC purposes. Note the different scales of the y-axes

For the official German CCS-Act, the P50 FC amounts diverge to plus infinity. However, in contrast to the macro results described above, the P05 FC amounts become negative in 2099 AD (Online Appendix, Fig. 9). This deviance to the macro results stems mainly from the increase in the economic effectiveness $\eta$ of temporary $\mathrm{CO}_{2}$ storage with time (Fig. 2) and the assumed time of transfer of responsibility, which occurs at $2080 \mathrm{AD}$ in the micro setup and 50 years after an injection pulse, and hence somewhat slower (while still in a realistic time period), in the macro setup. 


\section{Discussion of financial leakage risks and real-world legislation}

This section fulfills two entangled purposes. It discusses the stock values of financial climate risks from leakages of "well-managed" and "poorly managed" storage complexes, displayed in Figs. 3 and 4. However, the discussion takes into account the real-world regulatory environment spanned by the European CCS Directive and thus is able to provide an evaluation of official German and Hungarian financial precaution specifications.

\subsection{Dimensions of financial precautions in the CCS Directive}

Given the objective to hedge the state budget against a socialization of leakage-related financial risks, the regulator can firstly determine FS (or FC) amounts on basis of the P05 value of a storage complex's leakage probability distribution and relax financial precaution requirements once the CCS operator organizes robust risk-sharing agreements, for example, with other CCS operators or in the form of insurance instruments. If such risk pooling is in place and if there are no underlying serial errors, due to the law of large numbers, the mean compensation costs over a large number of independent storage complexes converge to their expected value. In reality, each storage complex is unique but its leakage distribution may nevertheless be accurately estimated.

Secondly, financial precaution can either take into account unavoidable leakages only ("well-managed" scenario) or both unavoidable and avoidable leakages ("poorly managed" scenario). The key questions here are (i) which level of trust the regulator has towards operators' willingness or ability to effectively provide "well-managed" storage solutions and (ii) to what extent the regulator believes that law-and-order regulation alone can effectively prevent the advent of "poorly managed" storage solutions or whether an explicit financial deterrent is necessary.

In the case "poorly managed" storage complexes are assumed as the basis of financial precaution arrangements, both the installment payments into the compensation payment fund and the resulting stocks increase roughly by a factor 50 relative to the "well-managed" storage assumption, while a shift from P50 value to P05 value of a given leakage distribution only increases financial precaution amounts by a factor of 2 to 3 . Thus, the question whether or not to hedge the state budget against both unavoidable and avoidable leakages is more decisive than whether or not to hedge it against the P50 or P05 value of a given leakage distribution.

\subsection{The Article 18 Transfer of Responsibility}

Assume that after a storage complex's leakage flux uncertainty reduction, the CCS operator reports a significant irremediable or unavoidable anticipated leakage flux such that one of the transfer conditions of 18(2)(a), (b), and (c), which determine whether "all available evidence indicates that the stored $\mathrm{CO}_{2}$ will be completely and permanently contained (CCS Directive, Article 18(1))," is persistently violated. Then, no matter whether the CA forces the operator to undertake corrective measures (CCS Directive, Article 16(1)) or whether the CA withdraws the storage permit (CCS Directive, Article 11) and initiates corrective measures on its own (CCS Directive, Article 16(3)), an indefinite liability of the CCS operator for the storage complex is prevailing. Thus, the operator remains liable for the storage site until his or her bankruptcy. 
One could adjust the CCS Directive to self-consistently include the circumstance of unavoidable or irremediable leakages by demanding in Article 18 (Transfer of Responsibility) the obligation from the operator to merely report an anticipated leakage behavior of the storage complex while strengthening Article 20 (Financial Mechanism) such that the FC shall be used to cover the full anticipated costs borne by the CA under its obligations after the transfer of responsibility. A sufficient build-up of (FS and) FC amounts could be ensured from a climate cost perspective by demanding from CCS operators, in the presence of risk-sharing agreements, to feed 3 to $6 \%$ of emissions-related revenues into a financial precaution fund that can then compensate maximally inflicted expected climate-related leakage costs (Figs. 2b, 3d, and 4d). By this modification, the regulation-induced business risk of an indefinite liability, and hence of bankruptcy in the case irremediable or unavoidable leakages are occurring, would be largely eliminated.

\subsection{The evolution of the compensation payment and the climate fund}

In the "well-managed" leakage scenario, the compensation payment fund amasses very low monetary amounts relative to the assumed prevailing carbon price, from around $0.2 \$$ in $2030 \mathrm{AD}$ to $0.8 \$$ in $2100 \mathrm{AD}$ per cumulatively stored ton of $\mathrm{CO}_{2}$, while the carbon price increases from $80 \$ / \mathrm{tCO}_{2}$ to $1867 \$ / \mathrm{tCO}_{2}$. However, due to the high cumulative value related to the $1420 \mathrm{Gt}$ of the stored $\mathrm{CO}_{2}$ by $2100 \mathrm{AD}$, the fund amasses up to around $0.2 \% \mathrm{GDP}_{2100 \mathrm{AD}}$ or globally around 1 trillion $\$$ - an amount that should in any case be amassed over the course of the twenty-first century in order to fully internalize the climate externality on CCS operators' budget sheets at the time of transfer of responsibility. Thus, under the CCS Directive and largescale CCS implementation, even the very low leakage rates on the order of $0.001 \%$ year, indicative for appropriately selected and well-managed storage sites, would translate into fund amounts that may be non-negligible.

In the context of uncertainty, the climate fund first grows roughly like the compensation payment fund of Figs. $3 \mathrm{~b}$ or $4 \mathrm{~b}$ but decreases gradually towards the "well-managed" compensation payment fund of Figs. 3a or 4a once uncertainty has been eliminated and storage complex integrity been proven along what is expected for "well-managed" storage complexes. Under the scenario of quick uncertainty reduction, the maximum financial amounts decrease roughly by a factor of 2 relative to the case of certainty projected in Figs. $3 b$ or $4 b$ (Online Appendix, Fig. 10). Hence, the reader may transfer the discussion of the compensation payment fund to the case of uncertainty accordingly.

\subsection{German and Hungarian financial precaution specifications}

For a single storage complex in which $1 \mathrm{MtCO}_{2}$ is sequestered per year from 2030 to $2060 \mathrm{AD}$, it only takes around 5 years for the expected value of the compensation payment fund to reach the Hungarian minimum FS amount of $731,000 \$$ in the "well-managed" leakage scenario (Fig. 4a). However, under the CCS Directive, expected climate costs for "well-managed" storage sites should in any case be reflected in FS amounts, while the CA should use the technique of "expected value" with care (European Commission and Climate Action DG 2011d). In the absence of robust risk sharing, the CA may even focus on the P05 compensation payment fund projections of Fig. 4a. Thus, the Hungarian minimum FS amount of $731,000 \$$ is only consistent with the precautionary design of the CCS Directive if quickly adjusted upward when $\mathrm{CO}_{2}$ injection proceeds or if combined with other effective FS instruments that can mobilize sufficient financial amounts when leakages occur. 
In contrast, the German financial precaution specifications, requiring that $3 \%$ of the emissions-related revenues are put aside into a deposit account, lead to yearly pay-ins from $\$ 2 \mathrm{M}$ in $2030 \mathrm{AD}$ to $\$ 9 \mathrm{M}$ in $2060 \mathrm{AD}$. This deviance reflects that the Hungarian minimum FS amount does not take into account climate-related leakage costs, while the strict German financial precaution specifications would be able to hedge the state budget against the expected value of climate-related leakage costs that result from avoidable leakages, where a FS present value on the order of tens to hundreds of millions of dollars is justified (Fig. 4b).

By construction, all anticipated climate costs are compensated if a share $(1-\eta)$ of emissions-related revenues is diverted into a compensation payment fund. If this share, however, must equate $3 \%$, i.e., $3 \%=(1-\eta(t))$, then the leakage entailed by an injection pulse at $2030 \mathrm{AD}$ could occur up to a rate of $l_{2030}=0.033 \% / \mathrm{yr}$ (derived from the formula on $\eta$ ). By $2100 \mathrm{AD}$ and beyond, the rate could be up to $l_{2100}=0.14 \% / \mathrm{yr}$. Thus, for the early twenty-first century CCS deployment, the P50 leakage rate of "poorly managed" storage sites of $0.066 \%$ / year (Online Appendix, Table 1) over the first hundred years is so large that lump-sum 3\% installment payments cannot fully hedge the state budget. For the late twenty-first century CCS deployment, this P50 leakage rate value is low enough, and only the P05 value of $0.18 \%$ year can potentially be a financial burden to the CA.

When cumulating yearly injection pulses over time, the expected value of leakagerelated climate costs can, for "poorly managed" storage complexes (Figs. 3d and 4d), be compensated over typical FS time periods (50-70 years), while FC amounts could compensate climate-related costs for up to a few decades but no longer. In conclusion, lump-sum 3\% emissions-related installment payments comply rather well with financial precaution requirements that are based on the expected value of leakage-related climate costs of "poorly managed" CCS sites. If regulators aim to hedge the state budget against the possibility that carbon prices stabilize rather late (in $2125 \mathrm{AD}$ ) or at unexpectedly high levels $\left(5750 \$ / \mathrm{tCO}_{2}\right)$, a share of 5 to $6 \%$ may also be justified (Fig. 3d). Given the Paris Agreement's objective of net zero emissions in the second half of this century, high carbon price levels generally would arise (already in the second half of this century) if CDR and other backstop technologies turn out to be less feasible than currently assumed in most IAMs.

Figures $3 \mathrm{c}$ and $4 \mathrm{c}$ show that, if regulators and firms do their jobs and "well-managed" storage complexes are indeed provided, the $3 \%$ emissions-related installment payments amass much larger funds than what are needed from a climate cost's point of view. Given the $4.5 \%$ yearly returns of the fund, yearly returns of $\$ 31.5 \mathrm{M}$ are yielded - an amount larger than a storage complex's operational monitoring costs which may be on the order of a few million dollars. Thus, further fund payouts need to be defined in order to prevent a slow drift into a state capitalistic economy, where a state-owned fund owns ever larger shares of national capital. One option is to allow performance-based paybacks to the CCS operator at the time of transfer of responsibility once the storage complex has been proven as "well-managed." This would reduce the disincentive for the operator to invest into CCS while providing a positive incentive to prove storage integrity.

In the official German CCS-Act, the 3\% installment payments are reserved as FC only. However, the discussion of combined FS and FC amounts for the "well-managed" leakage scenario still fully applies because compensation costs can in both cases be approximated as zero. For the "poorly managed" leakage scenario and the micro evolution of the CCS Act's FC amounts, the P50 value diverges to plus infinity and the P05 value to minus infinity, while for 
the macro evolution, both P50 and P05 FC amounts diverge to plus infinity (Online Appendix, Fig. 9), indicating that the financial precaution requirements under the German CCS-Act may be too strict. One reasonable relaxation of financial precaution specifications could be to devote the $3 \%$ installment payments to a combined FS and FC fund, i.e., a compensation payment fund, instead for FC purposes alone. However, if done so, it would be strictly necessary to allow for performance-based paybacks to the CCS operator because, otherwise, a moral hazard type of regulation would be erected where the operator is better off using up the FS share of the compensation payment fund instead of investing into storage safety enhancement measures.

\subsection{Modeling approach, sensitivities, and limitations}

How to evaluate real-world precautionary policies? In this article, first the existing (normative) precaution specifications of the European and German legislation were appreciated. Secondly, a model was built by approximating results of the scientific literature in a manner that aimed to keep the model as simple and transparent as possible (e.g., by an exogenous parameter integration) and as complex as necessary to reflect a span of plausible relevant alternative scenarios. Model simplicity facilitates speculations about relevant sensitivities. Scenario analysis aims to identify or motivate the risk perceptions reflected in policies. In the context of risk and uncertainty, science cannot decide which degree of precaution is normatively justified or unjustified. However, descriptive science that respects the inevitably normative nature of risk and uncertainty evaluation can aim to disentangle plausible consequences of normative assumptions from implausible ones. Society has no obvious motivation to hedge itself against implausible consequences but potentially a motivation to prevent or to hedge itself against plausible ones.

The results of this article are sensitive to two different types of parameters: "hard" and "soft" parameters. Hard parameters comprise assumptions about leakage behavior, carbon prices, the rate of return on investment, $\mathrm{CO}_{2}$ sequestration rates, GDP growth, and, in case the results are interpreted from the perspective of a given nation state, the deviance of plausible national parameters to global assumptions. Soft parameters comprise, e.g., societal risk, uncertainty and feasibility perceptions, assumptions about firm behavior and the potential of preventing fraud via law-and-order regulation, and questions about the confidence bias in the scientific community. Soft parameters can influence hard parameters: societal perceptions about CDR technologies impact real-world carbon prices. It is beyond the scope of this article to rigorously and systematically address these sensitivities. It is rather the aim to highlight the complexity that has to be addressed when evaluating leakage risks from the perspective of the regulatory end and to inform an intuition on plausible orders of magnitude.

One key model limitation stems from the leakage assumptions that, due to the fitting procedure, directly relate to the "storage security calculator" of Alcalde et al. (2018). The scenario of poorly managed CCS represents an "unrealistic scenario of $\mathrm{CO}_{2}$ storage being inadequately regulated and implemented in a region with a high risk of leakage along abandoned [legacy] wells." Besides abandoned legacy wells, the storage security calculator also included leakage through active injection wells and leakage via natural pathways. Given that the CCS Directive does provide a sound regulatory environment that puts a clear parallel focus on risk prevention besides hedging society against the financial risks that potentially may materialize, the scenario of poorly managed storage complexes is representative for a very high degree of regulatory precaution. 


\section{Summary and outlook}

Financial precaution instruments, designed to compensate all climate-related unavoidable leakage costs that are inflicted from adequately selected and well-managed CCS complexes, may need to mobilize globally up to around 1 trillion 2010 AD-based real dollars by 2100 AD or, equivalently, up to around $0.2 \%$ GDP. For a single storage complex, present costs of a few million to ten million dollars arise during the course of a CCS project. If the European CCS Directive was taken as indicative for the entire world, these amounts would increase by a factor of 2 in the absence of risk-sharing agreements, and in case the circumstance of avoidable leakages should be hedged in addition to unavoidable leakages, amounts may increase by a factor of 50 .

Therefore, the Hungarian minimum lump-sum financial security (FS) amounts below 1 million $\$$ are, after a few years of CCS operations, smaller than the expected value over the current distribution of climate-related unavoidable leakage compensation costs and almost negligibly small in case avoidable leakages occur. In contrast, the $3 \%$ emissions-related installment payments required from CCS operators under the German CCS-Act to be put into a financial precaution deposit account and handed over to the competent authority (CA) as a lump-sum financial contribution (FC) would suffice to compensate most of the total climaterelated costs that are induced by poorly managed storage complexes. However, the CCS-Act's FC amounts are much larger than necessary to cover costs after the transfer of responsibility for well-managed storage complexes. Thus, operators of well-managed storage complexes are subjected to regulation-induced business costs beyond what can be justified from externality arguments.

The European CCS Directive allows a transfer of responsibility from the CCS operator to the CA only if the storage complex's performance profile complies with ex ante specified criteria. One could largely eliminate the regulation-induced business risk of an indefinite liability in case a storage complex exhibits significant irremediable or unavoidable leakages if one generally allows the transfer of responsibility to occur after uncertainty reduction of a storage complex's leakage behavior, however, under the condition that FC payments shall be large enough to compensate all costs borne by the CA after the transfer of responsibility. From a climate compensation cost point of view, 3 to $6 \%$ of emissions-related installment payments into a financial precaution fund should, in the presence of risk pooling, largely suffice to build up adequate FS and FC amounts even if avoidable leakages occur.

Policy relevant financial modeling research should in the future firstly differentiate between irremediable and remediable leakage sources, taking into account remediation costs, secondly, go beyond climate-related leakage costs and include the full financial precaution obligations under the CCS Directive and, thirdly and maybe most importantly, be based on a robust analysis whether or not to assume unavoidable or avoidable leakage sources when determining amounts that potentially need to be mobilized by financial precaution instruments. For the latter, key questions are (i) which level of trust the regulator can have towards the scientific community's confidence level in estimating leakages and in mitigating risks via pre-injection monitoring and safety enhancement measures, (ii) which level of trust the regulator can have towards a CCS operator's willingness or ability to effectively provide "well-managed" storage solutions and (iii) to what extent the regulator should believe that law-and-order regulation alone can prevent avoidable leakage sources, respectively. 
Acknowledgments Many thanks to Hermann Held, who has provided a very free research environment in which this article's focus on real-world policy evaluation has become possible.

Funding Open Access funding enabled and organized by Projekt DEAL.

Open Access This article is licensed under a Creative Commons Attribution 4.0 International License, which permits use, sharing, adaptation, distribution and reproduction in any medium or format, as long as you give appropriate credit to the original author(s) and the source, provide a link to the Creative Commons licence, and indicate if changes were made. The images or other third party material in this article are included in the article's Creative Commons licence, unless indicated otherwise in a credit line to the material. If material is not included in the article's Creative Commons licence and your intended use is not permitted by statutory regulation or exceeds the permitted use, you will need to obtain permission directly from the copyright holder. To view a copy of this licence, visit http://creativecommons.org/licenses/by/4.0/.

\section{References}

Adelman D, Duncan I (2011) The limits of liability in promoting safe geologic sequestration of $\mathrm{CO}_{2}$. Duke Environ Law Policy Forum 22

Alcalde J, Flude S, Wilkinson M, Johnson G, Edlmann K, Bond C, Scott V, Gilfillan S, Ogaya X, Haszeldine R (2018) Estimating geological CO2 storage security to deliver on climate mitigation. Nat Commun 9(1). https://doi.org/10.1038/s41467-018-04423-1

Bolhassani B, Hovorka S, Hosseini S, Young M, Anderson J, Yang C (2017) Model-based assessment of the sitespecific cost of monitoring. Energy Procedia 114:5316-5319. https://doi.org/10.1016/j.egypro.2017.03.1652

Bundestag (2012) Gesetz zur Demonstration und Anwendung von Technologien zur Abscheidung, zum Transport und zur dauerhaften Speicherung von Kohlendioxid - vom 17.08.2012. Bundesgesetzblatt Jahrgang 2012 Teil I Nr. 38

Eiken O, Ringrose P, Hermanrud C, Nazarian B, Torp T, Høer L (2011) Lessons learned from 14 years of CCS operations: Sleipner, In Salah and Snøhvit. Energy Procedia 4:5541-5548. https://doi.org/10.1016/j. egypro.2011.02.541

European Commission (2014) Report from the Commission to the European Parliament and the Council on the implementation of Directive 2009/31/EC on the geological storage of carbon dioxide. COM(2014) 99 final

European Commission (2015) ANNEX - Report on review of Directive 2009/31/EC on the geological storage of carbon dioxide. COM(2015) 576 final

European Commission and Climate Action DG (2011a) Implementation of directive 2009/31/EC on the geological storage of carbon dioxide guidance document $1, \mathrm{CO} 2$ storage life cycle risk management framework. Publications Office. Luxembourg. OCLC: 1056429736

European Commission and Climate Action DG (2011b) Implementation of directive 2009/31/EC on the geological storage of carbon dioxide guidance document 2, characterisation of the storage complex, $\mathrm{CO} 2$ stream composition, monitoring and corrective measures. Publications Office Luxembourg OCLC 1056441284

European Commission and Climate Action DG (2011c) Implementation of directive 2009/31/EC on the geological storage of carbon dioxide guidance document 3, criteria for transfer of responsibility to the competent authority. Publications Office. Luxembourg. OCLC: 1056429254

European Commission and Climate Action DG (2011d) Implementation of directive 2009/31/EC on the geological storage of carbon dioxide guidance document 4, Article19 Financial Security and Article 20 Financial Mechanism. Publications Office Luxembourg OCLC 1044408404

Faure M, Partain R (2017) Carbon capture and storage: efficient legal policies for risk governance and compensation. The MIT Press, Cambridge, MA

Fuss S, Lamb W, Callaghan M, Hilaire J, Creutzig F, Amann T, Beringer T, de Oliviera GW, Hartmann J, Khanna T, Luderer G, Nemet G, Rogelj J, Smith P, Vicente J, Wilcox J, del Mar Zamora Dominguez M, Minx J (2018) Negative emissions - part 2: costs, potentials and side effects. Environ Res Lett 13(6): 063002. https://doi.org/10.1088/1748-9326/aabf9f

Gerard D, Wilson E (2009) Environmental bonds and the challenge of long term carbon sequestration. J Environ Manag 90(2):1097-1105. https://doi.org/10.1016/j.jenvman.2008.04.005 
Global CCS Institute (2018) The global status of CCS: 2017. Australia https:/www.globalccsinstitute.com/wpcontent/.../12/2017-Global-Status-Report.pdf. Accessed 15 May 2019

Ha-Duong M, Keith D (2003) Carbon storage: the economic efficiency of storing CO2 in leaky reservoirs. Clean Techn Environ Policy 5(3-4):181-189. https://doi.org/10.1007/s10098-003-0213-z

Hanley N, Shogren J, White B (2007) Environmental economics: in theory and practice. Palgrave Macmillan, Basingstoke [England]; New York, 2nd edition

Held H, Edenhofer O, Bauer N (2006) How to deal with risks of carbon sequestration within an international emission trading scheme. In: Proceedings of the 8th International Conference on Greenhouse Gas Control Technologies (Trondheim, Norway, 19-22 June 2006), issued on CD-ROM (ISBN-0-08-046407-6) by Elsevier/IEA GHG

Herzog H, Caldeira K, Reilly J (2003) An issue of permanence: assessing the effectiveness of temporary carbon storage. Clim Chang 293(59)

Horton J, Keith D, Honegger M (2016) Implications of the Paris Agreement for Carbon Dioxide Removal and Solar Geoengineering. Harvard Project on Climate Agreements, Viewpoints

IPCC (2005) Special report on carbon dioxide capture and storage. [Metz, B., O. Davidson, H.C. de Coninck, M. Loos, and L.A. Meyer (eds.)]. Prepared by Working Group III of the Intergovernmental Panel on Climate Change. Cambridge University Press. Cambridge

IPCC (2014) Technical Summary. In: Climate Change 2014: Mitigation of Climate Change. Contribution of Working Group III to the Fifth Assessment Report of the Intergovernmental Panel on Climate Change [Edenhofer, O., R. PichsMadruga, Y. Sokona, E. Farahani, S. Kadner, K. Seyboth, A. Adler, I. Baum, S. Brunner, P. Eickemeier, B. Kriemann, J. Savolainen, S. Schlömer, C. von Stechow, T. Zwickel and J. C. Minx (eds.)]. Cambridge University Press. Cambridge, United Kingdom and New York, NY, USA. OCLC: 922481101

IPCC (2018) Global Warming of $1.5^{\circ} \mathrm{C}$. An IPCC Special Report on the impacts of global warming of $1.5^{\circ} \mathrm{C}$ above pre-industrial levels and related global greenhouse gas emission pathways, in the context of strengthening the global response to the threat of climate change, sustainable development, and efforts to eradicate poverty [Masson-Delmotte, V., P. Zhai, H.-O. Pörtner, D. Roberts, J. Skea, P.R. Shukla, A. Pirani, W. Moufouma-Okia, C. Péan, R. Pidcock, S. Connors, J.B.R. Matthews, Y. Chen, X. Zhou, M.I. Gomis, E. Lonnoy, T. Maycock, M. Tignor, and T. Waterfield (eds.)]. In Press

Koelbl B, van den Broek M, Faaij A, van Vuuren D (2014) Uncertainty in carbon capture and storage (CCS) deployment projections: a cross-model comparison exercise. Clim Chang 123(3-4):461-476. https://doi. org/10.1007/s10584-013-1050-7

Piketty T (2014) Capital in the twenty-first century. The Belknap Press of Harvard University Press, Cambridge Massachusetts

Ringrose PS, Mathieson AS, Wright IW, Selama F, Hansen O, Bissell R, Saoula N, Midgley J (2013) The In Salah $\mathrm{CO}_{2}$ storage project: lessons learned and knowledge transfer. Energy Procedia 37:6226-6236. https://doi.org/10.1016/j.egypro.2013.06.551

Smith P, Davis S, Creutzig F, Fuss S, Minx J, Gabrielle B, Kato E, Jackson R, Cowie A, Kriegler E, van Vuuren D, Rogelj J, Ciais P, Milne J, Canadell J, McCollum D, Peters G, Andrew R, Krey V, Shrestha G, Friedlingstein P, Gasser T, Grübler A, Heidug W, Jonas M, Jones C, Kraxner F, Littleton E, Lowe J, Moreira J, Nakicenovic N, Obersteiner M, Patwardhan A, Rogner M, Rubin E, Sharifi A, Torvanger A, Yamagata Y, Edmonds J, Yongsung C (2015) Biophysical and economic limits to negative CO2 emissions. Nat Clim Chang 6(1):42-50. https://doi.org/10.1038/nclimate2870

Teng F, Tondeur D (2007) Efficiency of carbon storage with leakage: physical and economical approaches. Energy. 32(4):540-548. https://doi.org/10.1016/j.energy.2006.07.027

Vinca A, Emmerling J, Tavoni M (2018) Bearing the cost of stored carbon leakage. Front Energy Res 6:40. https://doi.org/10.3389/fenrg.2018.00040

Wilson E, Morgan M, Apt J, Bonner M, Bunting C, Gode J, Haszeldine R, Jaeger C, Keith D, McCoy S, Pollak M, Reiner D, Rubin E, Torvanger A, Ulardic C, Vajjhala S, Victor D, Wright I (2008) Regulating the geological sequestration of CO2. Environ Sci Technol 42(8):2718-2722. https://doi.org/10.1021/es087037k

Wilson E, Klass A, Bergan S (2009) Assessing a liability regime for carbon capture and storage. Energy Procedia 1(1):4575-4582. https://doi.org/10.1016/j.egypro.2009.02.277

Publisher's note Springer Nature remains neutral with regard to jurisdictional claims in published maps and institutional affiliations. 